\title{
A REVIEW OF IMPLEMENTATION OF BUILDING INFORMATION MODELING IN ELECTRICAL DESIGN
}

\section{OSCAR FLÓREZ- CEDIEL, JULIÁN R. CAMARGO L. \& MIGUEL A. AVILA A.}

Engineering Faculty, Universidad Distrital Francisco José de Caldas, Bogotá, Colombia

\begin{abstract}
This paper presents the fundamental concepts of the BIM methodology for engineering coordination as a response to the process of innovation and digitalization that the current energy world is demanding. Initially, the templates for the primary and secondary engineering requirements are defined for the implementation of code or automated subroutines. Later, the equipment and components databases are generated with their manuals and guide documents, which can be a switch as an element of an electrical substation or an electrical board of a house, which allow executing the basic and detailed engineering to finally obtain calculation memories, single line diagrams with their corresponding standards. In this way, each added and improved feature within the software has great advantages such as time reduction and remote access to the project since changes are generated at a general level of the structure involving minimal changes and at the same time identifying possible errors or necessary adjustments.

KEYWORDS: BIM, Engineering Base, Electrical Board, LoD, Revit
\end{abstract}

Received: Oct 06, 2020; Accepted: Oct 26, 2020; Published: Nov 28, 2020; Paper Id.: IJMPERDOCT202072

\section{INTRODUCTION}

The concept of modeling refers to a broad and general definition which refers to taking information from the real world, converting it into digital formats and using this digitalization to perform mathematical analysis, as well as understanding how different objects and/or structures are related. With the development of CAD software (computeraided design) as a tool that has been evolving sequentially according to the needs and challenges that arise, has allowed in recent years to model from small devices to more complex applications in large industries, it should be noted that the evolution of new technologies every day requires greater efficiency and product innovation so it has been improving the software interface to get all the information in the cloud and with the advantage of access from the work environment or remotely.

The new global work environments have been directed in the interaction of different agents and/or professionals in search of the same goal by integrating a whole set at the professional level in infrastructure projects has resulted in the BIM (Building Information Modeling) which goes beyond having a structure in three dimensions, transcending a virtual replica of the project with its physical and technical characteristics leading to a real process of construction [1]. Also, it analyzes the context in which the project is developed and with the great advantage that the different actors involved in the different stages of the project will work collaboratively within the same environment resulting in time reduction, optimizing the result, by having control of changes and automatic general adjustment of the structure of the different variables modified at any time in the software [2]. 
The integrated approach of the BIM model not only offers a significant increase in productivity but also serves as a basis for better-coordinated designs and construction processes based on an updated core model. This indicates that the BIM creation tool should completely cover the workflow independent of the modification. Therefore, it is a vital question whether the design, documentation, implementation and operation of the electrical design are supported by the BIM tool, starting with conceptual design to the documentation of the design, through construction, administration, construction management and finally, commissioning [3].

\section{BUILDING INFORMATION MODELING - BIM}

It is a unified platform that connects the data of any project in real-time from design to construction, which strengthens informed decision making and leads to more predictable and profitable results. The virtual model also provides the ability to simulate all aspects of the building, such as security, building comfort and energy efficiency, during all phases of the building's life cycle. The health and well-being of construction workers depend on these factors. By increasing transparency, risk can be minimized for investors, owners and operators. In the case that the primary source is commercial energy, the telecommunications company has its transformers or makes use of the electricity network from a transformer of the electricity company corresponding to the area where the base station is located [4].

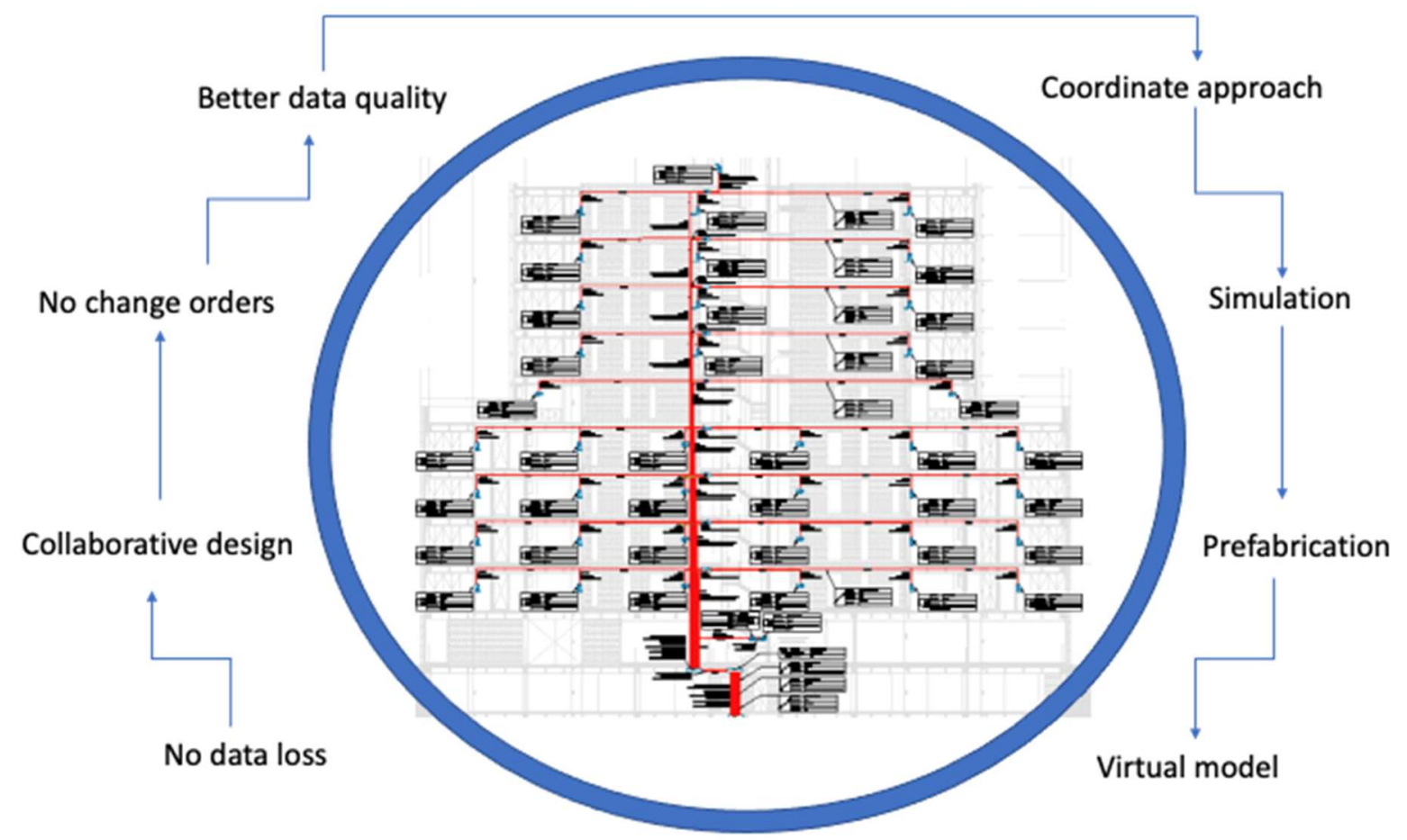

Figure 1: Digitization with BIM. Taken from [5]

\section{REVIT}

This software is designed specifically for Building Information Modeling (BIM), which allows design and engineering professionals to take a coordinated process from concept to construction with a model-based approach. It includes the functionality of all disciplines in a unified interface; enabling design and documentation through the generation of floor plans, elevations, sections, schedules, 3D views and representations. Optimizes structure performance by performing cost estimates and monitoring changes and performance over the life of the project and structure with the extension of design to 
virtual reality. Initially the classification and ordering are done within the database specifically for primary engineering. Therefore, it is important to keep in mind the concept of families in the software.

Revit families are all the elements that can be added to a project. They will have a series of properties according to the element and the function it fulfills in the model. It is essential to know that families are not the only elements that make up the model. The families contain several parameters that will give value to the virtual model, thanks to these can be made analysis, measurements, budgets and much more documentation essential for the development of the project [6].

Engineering Base (EB) is the platform for highly efficient engineering cooperation. EB is object-oriented, with the SQL database used in the computer-aided engineering tools (CAE) that offer electrical engineering, instrumentation and energy solutions for different industries. This pioneering software technology ensures high availability and intuitive handling during the process.

Six main stages are identified in the development of the project with a BIM environment and are called dimensions. In the first dimension (Scratch Point) the origin of the project is given, in which the corresponding processes are structured for its later implementation. In the second dimension (Vector), the design and calculation activities for the basic development of the project are carried out. In the third dimension (Modelling) the data and parameters of the model are introduced for all the related disciplines. The fourth dimension (Planning) plans the project and all the work that integrates it to carry it out, through Gantt diagrams or similar. In the fifth dimension (Cost Control), the costs and related expenses are estimated to determine the profitability and make the necessary adjustments in the previous dimensions. Finally, the sixth dimension (Sustainability) allows estimating the management of resources and the possibilities of saving for decision making in several aspects such as environmental, energy, among others.

The primary engineering that starts with an offer to the client according to the needs and/or requirements of the same, where the project cycle starts and the need to enhance the software used is taken into account to reduce times through templates and models. Although the stage and changes to be made sequentially must be taken into account. Within this area the LOD (Level of Development) is handled, which is in charge of identifying the stage of the project with the respective information and its representation in the software to continue its elaboration and allowing to make the appropriate changes, highlighting those that possibly generate problems in the infrastructure [7]. Bearing in mind that elements will be added to the design here, it is necessary to have the databases of each device where each equipment is specified with its respective families, categories, characteristics and its parameterization in such a way that everything is registered and all the possible knowledge of the project is known. This means that the more information I have about the project and the closer it will be to its virtual construction to the real one. The different levels are specified below and presented in Figure 2 [8].

LOD 100: The model element can be represented graphically in the model with a symbol or other generic representation, but does not meet the requirements for LOD 200. Information related to the model element (i.e., cost per square foot, HVAC tonnage, etc.) can be derived from other model elements.

LOD 200: The model element is represented graphically within the model as a generic system, object or assembly with approximate quantities, size, shape, location and orientation. Non-graphic information can also be attached to the model element.

LOD 300: The model element is represented graphically within the model as a specific system, object or set in terms of quantity, size, shape, location and orientation. Non-graphic information can also be attached to the model element. 
LOD 350: The model element is represented graphically within the model as a specific system, object or set in terms of quantity, size, shape, orientation and interfaces to other building systems.

LOD 400: The model element is represented graphically within the model as a specific system, object or assembly in terms of size, shape, location, quantity and orientation with detailed, manufacturing, assembly and installation information. Non-graphical information can also be attached to the model element.

LOD 500: The model element is a field verified representation (i.e., how it was built) in terms of size, shape, location, quantity, and orientation. Non-graphic information may also be attached to the Model Element.

Lod 100

Concept Design

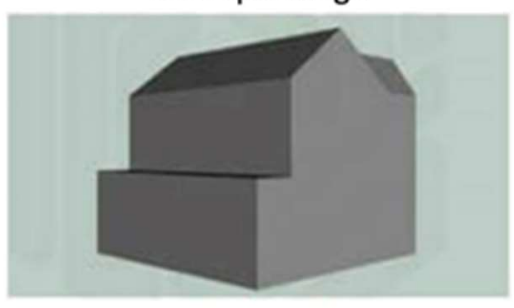

Lod 300

Presentation

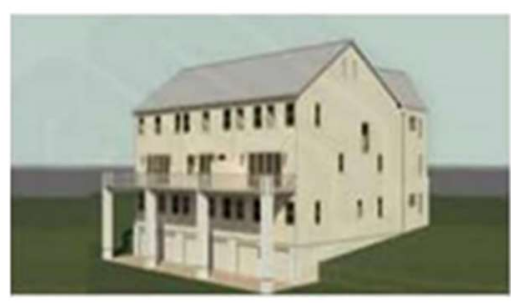

Lod 200

Design developed

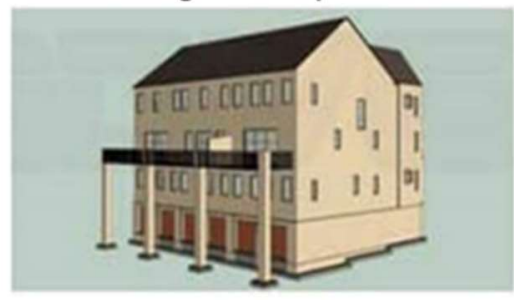

Lod 400

Building

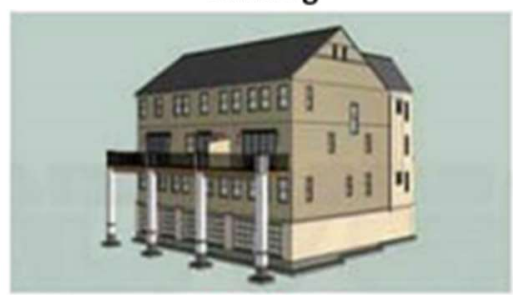

Lod 200/300 Building documentation

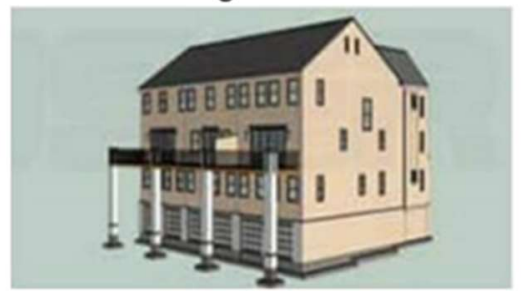

Lod 500

Modeling As Built

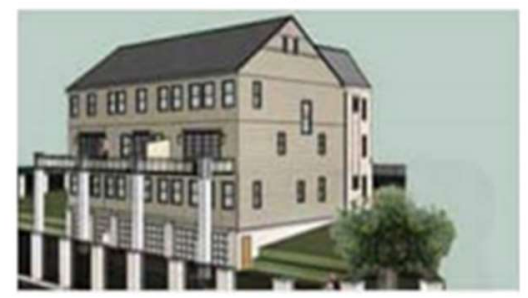

Figure 2: LOD levels. Taken from [9]

\section{IMPLEMENTATION OF BIM IN ELECTRICAL DESIGN}

It begins with the identification of each of the company's guidelines and how the different projects that are necessary to carry out the design processes are presented, followed by training in the primary and secondary energy design software "Engineering Base" and "Revit". Next, the database of the equipment and templates that make up the design engineering is collected, in which the manuals and interoperability of these elements are reviewed so that if it is necessary to modernize or adapt them, this is done using the new software. Afterward, the equipment classification stage is continued according to its functionality and to identify the requirements according to their technical specifications.

Taking into account all of the above, we will proceed to develop schematics and Z-diagrams of the equipment used and to complete the existing database. The Z-diagrams are the schematics of the protection equipment where the connection points, terminals, binary inputs and outputs, power supply among others, are located. They are used to identify and cross equipment connections. To deliver the consolidated project, finally, a deliverable will be made explaining the procedure followed for the development of the equipment and that it is the guide manual for the development of future models that are required in the continuous supply of the system database. The information in the table is taken to a spreadsheet that will later be imported into the Revit software. Then use it to size and characterize the equipment that the customer requires. This process should not be lost sight of for the equipment is by way of example as there are different primary engineering devices 
previously named to which the same procedure was done. From the organization and debugging of the databases used by the engineering area within the organization, it became necessary to apply a structure and categorization of equipment, models and documentation implemented in the phases of the primary engineering cycle, as shown in Figure 3.

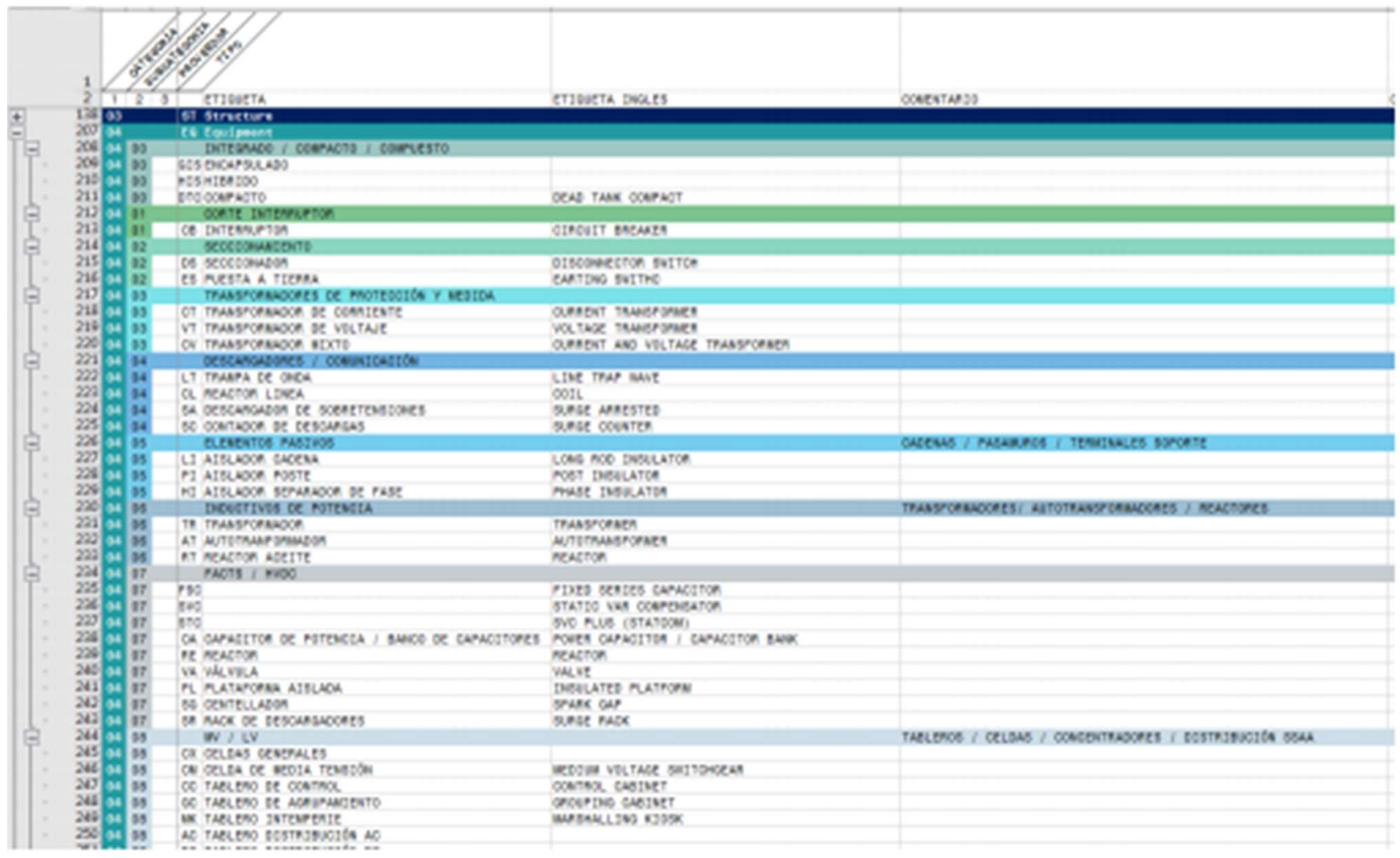

Figure 3: Codification of primary engineering equipment

According to the classification, the following properties are given to understand the database. The first number refers to the type of structure that is being used, the process was developed only with the code 04 to which the power equipment is assigned such as switches, disconnectors, surge arresters, instrument transformers (CT's and PT's), in addition to many compensation systems such as FACTS, capacitor banks and inductive elements. Also in this category are secondary engineering equipment such as photovoltaic panels, batteries, chargers, medium voltage cells, among others. Together, the categorization includes civil and architectural works.

For the database, all the available information on the equipment was organized in duly cataloged folders. Bearing in mind that the type of structure of each piece of equipment belongs to a family or subcategory which is represented by the second digit, the reading and handling of information in the database become more fluid and with a better understanding.

Specifically, this second digit contains components and families such as CT's and PT's, sectionalizes, passive elements, HVDC, among others. It is worth mentioning that there are different folders containing information about the general design of the substation, that is why we talk about subcategories since within each main folder there is equipment to be used with its respective description and technical specifications. The design must go hand in hand with the information of the equipment being modeled, that is why with the BIM methodology the equipment can be modified if required. Figure 4 shows the information provided by a manufacturer. 


\begin{tabular}{|c|c|c|c|c|c|c|c|c|c|c|c|c|c|c|}
\hline PTF_SDT_1077D & 45 & $13200 \mathrm{~V} / 226-130.5 \mathrm{~V}$ & 1258 & 1078 & & 1239 & 394 & 472 & 1082 & 887 & Dyn5 & Ojo & 260 & 684 \\
\hline PIt_SUI_10/80 & 75 & $11400 \mathrm{~V} / 214-123.6 \mathrm{~V}$ & 1322 & 1176 & & 1413 & 386 & 520 & 1092 & 889 & Dyn5 & Pala 4 Huecos & 292,4 & 774 \\
\hline PTF_SDT_1079D & 75 & $13200 \mathrm{~V} / 226-130,6 \mathrm{~V}$ & 1258 & 1078 & & 1239 & 394 & 472 & 1082 & 887 & Dyn5 & Pala 4 Huecos & 250 & 729 \\
\hline PTF_SDT_1080D & 112,5 & $13200 \mathrm{~V} / 214-123.6 \mathrm{~V}$ & 1258 & 1207 & & 1208 & 394 & 472 & 1082 & 887 & Dyn5 & Pala 4 Huecos & 255 & 799 \\
\hline PTF_SDT_1081D & 112,5 & $11400 \mathrm{~V} / 214-123,7 \mathrm{~V}$ & 1258 & 1287 & & 1208 & 394 & 472 & 1082 & 887 & Dyn5 & Pala 4 Huecos & 253 & 803 \\
\hline PTF_SDT_1082D & 112.5 & $13200 \mathrm{~V} / 226-130.6 \mathrm{~V}$ & 1322 & 1200 & & 1453 & 386 & 520 & 1092 & 889 & Dyn5 & Pala 4 Huecos & 253.4 & 769 \\
\hline PTF_SDT_1083D & 150 & $11400 \mathrm{~V} / 214-123.6 \mathrm{~V}$ & 1258 & 1207 & & 1208 & 394 & 472 & 1072 & 887 & Dyn5 & Pala 4 Huecos & 245 & 859 \\
\hline PTF_SDT_1084D & 150 & $13200 \mathrm{~V} / 226-130.5 \mathrm{~V}$ & 1258 & 1207 & & 1218 & 394 & 472 & 1072 & 888 & Dyn5 & Pala 4 Huecos & 248 & 895 \\
\hline PTF_SDT_1085D & 150 & $13200 \mathrm{~V} / 214-123.6 \mathrm{~V}$ & 1322 & 1240 & & 1413 & 386 & 520 & 1092 & 889 & Dyn5 & Pala 4 Huecos & 248 & 822 \\
\hline PTF_SDT_1086D & 225 & $13200 \mathrm{~V} / 214-123.6 \mathrm{~V}$ & 1323 & 1479 & & 1281 & 456 & 474 & 1131 & 944 & Dyn5 & Pala 4 Huecos & 352 & 1132 \\
\hline PTF_SDT_1087D & 225 & $11400 \mathrm{~V} / 456-263.3 \mathrm{~V}$ & 1398 & 1517 & & 1452 & 536 & 520 & 1168 & 1069 & Dyn5 & Pala 4 Huecos & 444 & 1229 \\
\hline PTF_SDT_1088D & 225 & $11400 \mathrm{~V} / 214-123.6 \mathrm{~V}$ & 1328 & 1397 & & 1261 & 464 & 472 & 1156 & 957 & Dyn5 & Pala 4 Huecos & 355 & 1154 \\
\hline PTF_SDT_1089D & 225 & $13200 \mathrm{~V} / 456-263.3 \mathrm{~V}$ & 1428 & 1350 & & 1580 & 526 & 444 & 1170 & 1000 & Dyn5 & Pala 4 Huosos & 505,7 & 1255 \\
\hline PTF_SDT_1090D & 225 & $13200 \mathrm{~V} / 226-130.5 \mathrm{~V}$ & 1328 & 1476 & & 1261 & 464 & 472 & 1156 & 957 & Dyn5 & Pala 4 Huecos & 343 & 1116 \\
\hline PTF_SDT_1091D & 300 & $13200 \mathrm{~V} / 226-130.5 \mathrm{~V}$ & 1328 & 1371 & & 1261 & 479 & 472 & 1156 & 957 & Dyn5 & Pala 4 Huecos & 349 & 1243 \\
\hline PTF_SDT_1002D & 300 & $11100 \mathrm{~V} / 156.263 .3 \mathrm{~V}$ & 1277 & 1000 & & 1617 & 527 & 545 & 1277 & 1000 & Dyns & Pula 4 Huecus & 473,4 & 1373 \\
\hline PTF_SDT_1093D & 300 & $13200 \mathrm{~V} / 214-123.6 \mathrm{~V}$ & 1328 & 1492 & & 1281 & 479 & 472 & 1156 & 957 & Dyn5 & Pala 4 Huecos & 379 & 1279 \\
\hline PTF_SDT_1094D & 400 & $13200 \mathrm{~V} / 214-123.6 \mathrm{~V}$ & 1368 & 1516 & & 1370 & 544 & 472 & 1162 & 997 & Dyn5 & Pala 4 Huecos & 475 & 1541 \\
\hline PTF_3DT_1095D & 400 & $11400 \mathrm{~V} / 450-203.3 \mathrm{~V}$ & 1398 & 1335 & & 1020 & 530 & 520 & 1108 & 1009 & Dyns & Pala 4 Huecos & 432 & 1410 \\
\hline PTF_SDT_1096D & 500 & $11400 \mathrm{~V} / 214-123.6 \mathrm{~V}$ & 1408 & 1603 & & 1360 & 504 & 472 & 1162 & 1037 & Dyn5 & Pala 4 Huecos & 462 & 1634 \\
\hline PTF_SDT_1098D & 630 & $13200 \mathrm{~V} / 214-123.6 \mathrm{~V}$ & 1540 & 1752 & & 1700 & 536 & 520 & 1313 & 1169 & Dyn5 & Pala 4 Huecos & 611,7 & 1923 \\
\hline \multirow[b]{2}{*}{ REFERENCIA } & kVA & AT / BT (Vacio) & \multicolumn{8}{|c|}{$\mathrm{mm}$} & \multirow{2}{*}{$\begin{array}{l}\text { GRUPO DE } \\
\text { CONEXIÓN }\end{array}$} & \multirow[b]{2}{*}{ CONECTOR BT } & $\mathbf{L}$ & $\mathrm{kg}$ \\
\hline & POTENCIA & TENSION & A & B & c & D & $\mathbf{E}$ & $\mathbf{F}$ & G & H & & & $\begin{array}{l}\text { VOLUMEN } \\
\text { ACEITE }\end{array}$ & $\begin{array}{l}\text { PESO } \\
\text { TOTAL }\end{array}$ \\
\hline
\end{tabular}

Figure 4: Equipment specifications

The information in the table is taken to a spreadsheet that will later be imported into the Revit software. Then the transformer required by the customer is sized and characterized. This process should not be lost sight of for the equipment is by way of example since there are different primary engineering devices previously named to which the same procedure was done.

With the technical specification tables for the different equipment already digitized, the BIM methodology can be used because when changing the voltage level or the transformer (equipment), the program will look for the parameters that are modified and update the conditions that depend on them, for example, the model was created with a "D" parameter which refers to the height of the same, but from this same parameter certain conditions are created which coordinate different heights that the transformer has, so just by modifying a parameter, the height of the radiator and other information about it varies.

\section{CONCLUSIONS}

The implementation of new technologies in the development of processes within the company allows solutions to customers in less time, efficiency and quality. Therefore, the improvement and in this case the use of BIM methodology for the development of projects marks an important point between the conventional and the modern in terms of infrastructure construction and interaction of the different professionals involved.

The digitalization process is providing a huge technological advance. About the energy field, the electricity demand has exponential growth and the challenges that the company has is to provide solutions in a short time but efficient and this is achieved with professionals capable of providing answers and solutions to the challenges that arise.

Each added and improved feature within the software has great advantages such as time reduction and remote access to the project since changes are generated at a general level of the structure involving minimal changes while identifying possible errors or adjustments needed to adapt the structure. 


\section{ACKNOWLEDGMENTS}

The authors would like to thank the Universidad Distrital Francisco José de Caldas and the LASER research group that supported the development and testing of the project.

\section{REFERENCES}

1. Marzouk, M., \& Othman, A. (2020). Planning utility infrastructure requirements for smart cities using the integration between BIM and GIS. Sustainable Cities and Society, 102120.

2. Doherty, M., \& Esmaeili, B. (2020, March). Application of Artificial Intelligence in Electrical Safety. In 2020 IEEE IAS Electrical Safety Workshop (ESW) (pp. 1-6). IEEE.

3. Forcael, E., Martinez-Rocamora, A., Sepúlveda-Morales, J., García-Alvarado, R., Nope-Bernal, A., \& Leighton, F. (2020). Behavior and Performance of BIM Users in a Collaborative Work Environment. Applied Sciences, 10(6), 2199.

4. Alhamami, A., Petri, I., Rezgui, Y., \& Kubicki, S. (2020). Promoting Energy Efficiency in the Built Environment through Adapted BIM Training and Education. Energies, 13(9), 2308.

5. https://siemens.com/global/en/home/products/buildings/digitalization/bims/5

6. Jiang, J., Shen, X., Shi, J., \& Jiang, Z. (2020, November). A Hybrid Approach to Semi-Automatic Conversion of 3D Point Cloud Data to Building Information Model. In Construction Research Congress 2020: Infrastructure Systems and Sustainability (pp. 408-417). Reston, VA: American Society of Civil Engineers. ISO 14224, (2016). Petroleum, petrochemical and natural gas industries - Collection and exchange of reliability and maintenance data for equipment.

7. https://www.redstackshop.com.au/levels-of-development-levels-of-detail-lod-explained.

8. https://www.srinsofttech.com/bim-level-of-development-lod-300-400-500.html 

